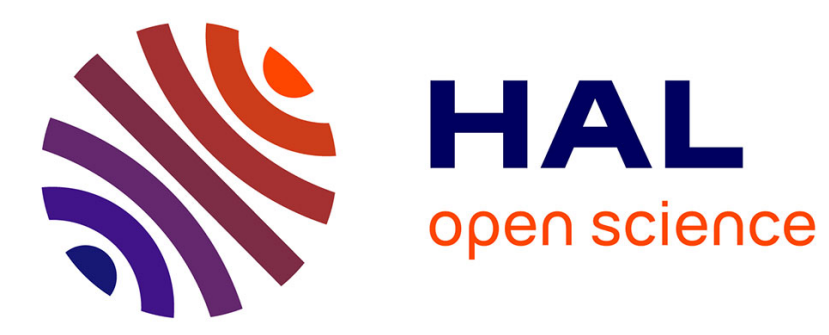

\title{
Spectrum and Attenuation of Non-Linear Surface Magnetostatic Spin Waves in Ferrite Films
}

\author{
A. Kozhevnikov, Yu. Filimonov, S. Nikitov
}

\section{To cite this version:}

A. Kozhevnikov, Yu. Filimonov, S. Nikitov. Spectrum and Attenuation of Non-Linear Surface Magnetostatic Spin Waves in Ferrite Films. Journal de Physique IV Proceedings, 1997, 07 (C1), pp.C1401-C1-402. 10.1051/jp4:19971162 . jpa-00254808

\section{HAL Id: jpa-00254808 https://hal.science/jpa-00254808}

Submitted on 1 Jan 1997

HAL is a multi-disciplinary open access archive for the deposit and dissemination of scientific research documents, whether they are published or not. The documents may come from teaching and research institutions in France or abroad, or from public or private research centers.
L'archive ouverte pluridisciplinaire HAL, est destinée au dépôt et à la diffusion de documents scientifiques de niveau recherche, publiés ou non, émanant des établissements d'enseignement et de recherche français ou étrangers, des laboratoires publics ou privés. 


\title{
Spectrum and Attenuation of Non-Linear Surface Magnetostatic Spin Waves in Ferrite Films
}

\author{
A.V. Kozhevnikov, Yu.A. Filimonov and S.A. Nikitov* \\ Institute of Radioengineering \& Electronics, Saratov Branch, Russian Academy of Sciences, 38 Zelenaya \\ st., 410019 Saratov, Russia \\ * Institute of Radioengineering \& Electronics, Russian Academy of Sciences, 11 Mokhovaya st., \\ 103907 Moscow, Russia
}

\begin{abstract}
Dispersion and attenuation of non-linear surface magnetostatic waves (MSSW) propagating in thin yttrium-irongamet (YIG) ferrite films have been studied both experimentally and theoretically. They were defined from the amplitude and phase alterations of the wave as it traveled along the "non-equilibrium" part of the film. At the border of such a non-equilibrium part the wave power is equal to the threshold value. The value for the threshold power is defined by the first- and second-order parametric decay processes for the MSSW.
\end{abstract}

\section{INTRODUCTION}

Non-linear magnetostatic spin waves become widely used now for the application in microwave region of the spectrum [1]. However, the wave dispersion and attenuation strongly differ in the non-linear case in comparison with the linear wave propagation [2-4]. To connect the measured alterations in the wave amplitude and phase as it has been done in the linear regime it is possible if one knows the distance $L$ where the wave is non-linear. Usually this distance is unknown and it is quite difficult to define it. In the present work we introduce the approach to measure the phase and power alterations within the non-equilibrium part of the film based on the two-pumpings method.

\section{EXPERIMENT}

Experiments were provided using the delay line configuration with three microstrip transducers (Fig. 1). The distance $S$ between transducers 1 and 2 could be altered between 0.25 to $4 \mathrm{~mm}$, the distance between transducets 2 and 3 was permanent and equal to $4 \mathrm{~mm}$. The YIG film was flipped onto the transducers and the crystallographic direction [110] of the crystal was parallel to the transducers. The film with the thickness $\mathrm{d}=5.05 \mu \mathrm{m}$ was grown on the gadolinium-gallium-garnet substrate. Its magnetization was $4 \pi M=1795 \mathrm{O} e$ and the ferromagnetic resonance line $\Delta H=0.2 \mathrm{Oe}$. The external magnetic field was parallel to the transducers and could be altered between 560 and $700 \mathrm{Oe}$.

The pumping signal with the frequency $3.56 \mathrm{GHz}$ and the power $60 \mathrm{~mW}$ was launched to the transducer 2 or 1 . In the same time two other transducers were used to investigate the amplitude and phase of the probe signal with the frequency from 3 to $5.6 \mathrm{GHz}$ and the power from 0.01 to $1 \mu \mathrm{W}$ In the case when on the way of the probe signal the pumping wave creates parametric spin waves due to parametric instability decay processes, the amplitude and phase of the probe wave were altered. We were interested in the dependence of the amplitude and phase of the probe wave on the external field, mutual configuration of the exciting transducers and the supercriticality of the pumping wave power. The MSSW wave power was typically only the 0.05 to 0.2 fraction of the power launched to the antenna. The rest of the power was reflected from the transducer.

To define the dimensions of the non-equilibrium part of the film the pumping signal was launched to the transducer 1 and the transducers 2 and 3 were used to analyze the probe signal characteristics (Fig. 1.). The pumping MSSW induces the nonequilibrium magnetization in the part of the film close to the transducer 1 . Its length $L$ is combined from the two lengths $L^{+}$ and $L^{-}$respecting to the MSSW propagation in the direct and reverse directions. In the case when the transducer 2 is inside the non-linear part of the film ( $<<L^{+}$), the absorption bands appear in the amplitude-frequency characteristic of the transmitted signal. If the transducer 2 is outside the non-linear part of the film ( $\mathrm{S}>L^{+}$), the probe wave characteristics are not altered. The measured dimensions of the non-equilibrium part of the film as the function of the magnetic field and the supercriticality level in $10 \mathrm{~dB}$ are shown in Fig. 2. The values for the power threshold are also presented in Fig.2. For the magnetic field less than $588 \mathrm{Oe}$, where the conditions for 3-magnon parametric decay are fulfilled, the power threshold is about 2 to $6 \mu \mathrm{W}$, and the length of the non-linear part is from 2 to $3 \mathrm{~mm}$. For the fields more than $590 \mathrm{Oe}$, where the 4 magnon parametric decay is only permitted, the power threshold is about 60 to $100 \mu W$ and the length of the non-linear part is from 4 to $6 \mathrm{~mm}$. To measure the MSSW dispersion in the non-linear region the pumping signal was launched to the 
transducer 2 and the probe signal - to the transducer 1 . Fig. 3 presents the data of the dependence of the non-linear frequency shift on the wave number for the pumping power $10 \mathrm{~mW}$ and the two values of magnetic field 583 and 595 Oe, respecting to the 3-magnon and 4-magnon parametric decay. The value for the frequency shift in the case of 4-magnon decay coincides with the calculated value based on the theory developed in [5].

\section{CONCLUSION}

The approach for study the non-linear properties of traveling magnetostatic waves in ferrite films developed in the present work permits to define very precisely the threshold values for the power in parametric processes. Along with other methods studying the spectrum of the transmitted non-linear waves and amplitude-frequency characteristics, it becomes a powerful method for investigation of non-linear properties of ferrite films.

\section{Acknowledgments}

Financial support from the Russian Foundation for Basic Research, Grant 96-02-16168-a is gratefully acknowledged.

\section{References}

[1]. Boardman A.D., Gulyaev Y.V. and Nikitov S.A. Jap. J. Appl. Phys. 27 (1988) pp.L2438-2441.

[2]. Yukawa T. and Abe K. J. Appl. Phys, 45 (1974) pp.3146-3153.

[3]. Gulyaev Y.V., Zilberman P.E., Nikitov S.A. and Temiryazev A.G. Sov, Phys. Solid State 28 (1986) pp.2774-2779.

[4]. Anisimov AN., Gurevich A. G. and Chivileva O.A. Sov. Phys. Solid State 32 (1990) pp.1622-1627.

[5]. Boardman A.D. and Nikitov S.A. Phys. Rev. B38 (1988) pp.11444-11451.

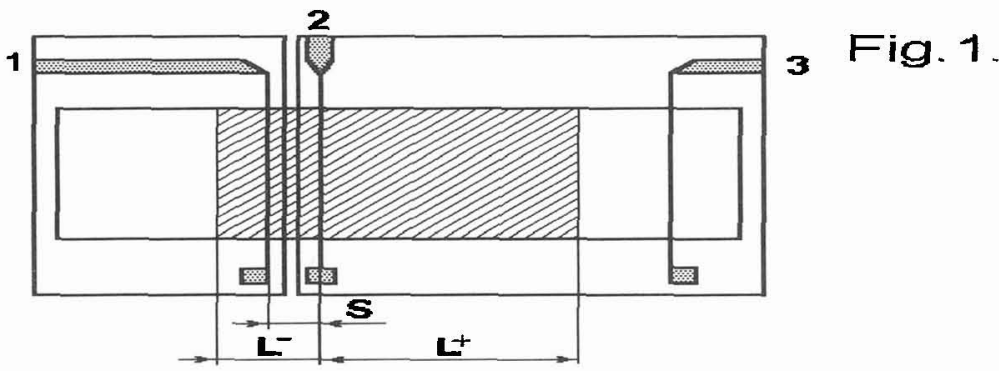

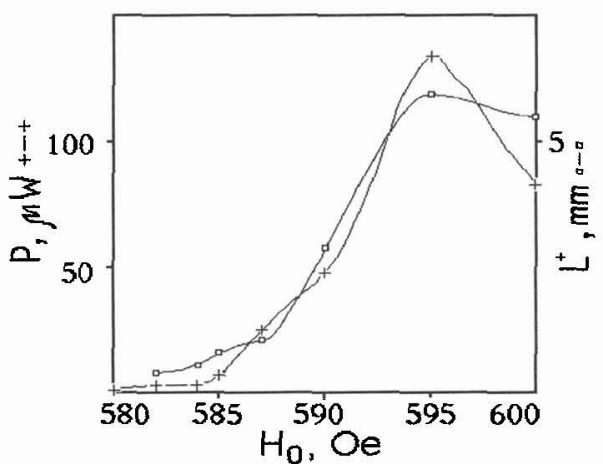

Fig. 2.

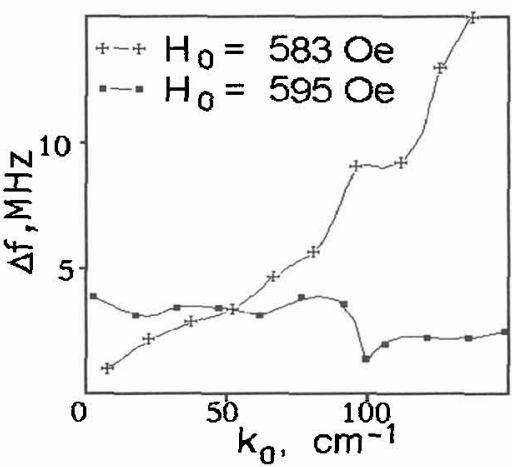

Fig. 3. 